\title{
Cone beam computed tomography in assessment on pharynx effects of orthopedic-surgical treatment - a review of the literature
}

Thais Moura Guimarães ${ }^{1}$

Rita Catia Bariani ${ }^{2}$

Sergio Giamas Iafigliola ${ }^{1}$

Clara Moura Guimarães ${ }^{1}$

Cauby Maia Chaves Junior ${ }^{3}$

Otávio Ferraz ${ }^{1}$

Mario Cappellette Junior ${ }^{2}$

Thays Crosara Abraão-Cunha ${ }^{1}$

Cibele Dal-Fabbro ${ }^{1}$

Rowdley Rossi ${ }^{1}$

Lia Bittencourt ${ }^{1}$

Reginaldo Raimundo Fujita ${ }^{2}$

Sergio Tufik ${ }^{1}$

Gustavo Moreira ${ }^{1}$

${ }^{1}$ UNIFESP, Departmento de

Psicobiologia - São Paulo - São Paulo

- Brazil.

${ }^{2}$ UNIFESP, Departmento de

otorrinolaringologia e cirurgia de cabeça e pescoço - São Paulo - São Paulo -

Brazil.

${ }^{3}$ UFC, Departamento de Clínica

odontológica - Fortaleza - Ceará - Brazil.

Corresponding author:

Thais Moura Guimarães.

E-mail: thaisdemouraguimaraes@gmail. com

Received: november 8, 2018; Accepted: february 5, 2019

\begin{abstract}
The cone beam computed tomography (CBCT) image provides clear differentiation of soft tissues from empty spaces. This paper presents a literature review to evaluate the effects of orthopedic and surgical treatment on the pharyngeal dimension by CBCT. It was concluded that treatments involving dentofacial orthopedics and orthognathic surgery have been related with an increase in the upper airway volume. Standardized capturing of tomographic images and more controlled and randomized studies are necessary.
\end{abstract}

Keywords: Cone Beam Computed Tomography; Pharynx; Orthognathic Surgery; Orthodontics. 


\section{INTRODUCTION}

The morphology of the human pharynx continues to be the object of different studies that seek to understand its functioning and size in several physiological functions ${ }^{1}$. The pharynx is a complex structure and has multiple functions that include breathing, speech and swallowing ${ }^{1}$. It has an intrinsic stiffness, but is quite vulnerable to large variations in its diameter ${ }^{2-4}$. Some therapeutic approaches seem to influence major changes in pharyngeal configuration ${ }^{2}$. There are currently investigations to quantify the effects of these approaches, including the impact of orthopedic and maxillomandibular surgical treatment on upper airway size and volume ${ }^{2}$.

The cone beam computed tomography (CBCT) is an important tool to evaluate the size of the upper airway, and is used to describe the mechanism of action of orthopedic/surgical treatments ${ }^{5}$. The CBCT presents a well-defined limit between soft tissues and empty spaces, and the airway is easily observed ${ }^{6}$.

This paper presents a literature review about the use of CBCT in evaluation of dentofacial orthopedics and orthognathic surgical effect on upper airway dimension.

\section{REVIEW}

\section{Analysis of upper airway by CBCT}

The cone beam computed tomography (CBCT) provided great advances in Dentistry due to its sharpness, practicality, low cost, and low radiation dose 7 . Shortcomings as distortion, magnification and superimposition of structures were common in bidimensional images, which limited the investigations on the upper airway ${ }^{6}$. The CBCT was introduced as an alternative to magnetic resonance imaging, due to its lower radiation dose, lower cost, easy access and shorter time required for achievement of images ${ }^{8}$.

Even though the soft tissue imaging on CBCT is inferior compared to magnetic resonance, the delineation of the upper airway is accurate and easy ${ }^{6}$. The CBCT presents a clear limit between soft tissues and empty spaces, which is important to evaluate the upper airway ${ }^{6}$. Conversely, the magnetic resonance imaging differentiates the types of soft tissues as muscles, connective tissue and fat, which is not possible on $\mathrm{CBCT}^{6}$. Based on the current yet limited evidence, evaluation of the pharyngeal airway volume by CBCT presents good intra- and interexaminer reliability?.

During image acquisition, however, some rules have been discussed to avoid biases that alter the size of the upper airway while achieving the tomographic image. The pharynx is a dynamic flexible tube whose diameter is altered during some functions ${ }^{10}$. Factors as head posture, breathing cycle and swallowing stages have been discussed as aspects that require guidelines for good reproducibility the image acquisition ${ }^{10}$.

There is increasing discussion on the importance of standardization and control of head posture during acquisition of CBCT. Gurani et al. ${ }^{7}$ mention that the dimension and morphology of the upper airway depends on the head posture and cranio-cervical inclination during image acquisition. The authors performed a systematic review to evaluate standardized positioning methods during acquisition, and observed poor standardization of head and tongue posture in CBCT for analysis of the upper airway ${ }^{7}$. It should be highlighted that this is a significant problem, since the lack of standardization impairs the reproducibility ${ }^{7}$. Conversely, association of $\mathrm{CBCT}$ airway images and health outcomes are a strategy to reinforce the imaging results.

\section{Effect of dentofacial orthopedics on the airway volume Rapid maxillary expansion}

The rapid maxillary expansion is an alternative coadjutant method for the treatment of obstructive sleep apnea (OSA) in children and adolescents. A recent meta-analysis demonstrated the positive effect of rapid maxillary expansion, evidencing a reduction of 6.9 in the apnea/hypopnea index ${ }^{11}$.

Studies evaluating the increase of the upper airway after rapid maxillary expansion by CBCT in children and adolescents with OSA observed an increase in total pharyngeal volume after treatment ${ }^{12-14}$. While Caprioglio et al. ${ }^{13}$, Mordente et al. ${ }^{15}$ and Kim et al. ${ }^{16}$ related this increase to the nasopharynx volume, Fastuca et al. ${ }^{12}$ related this increase to the three pharyngeal thirds.

In children without OSA, the results on the effect of rapid maxillary expansion on the upper airway volume by CBCT are controversial. Two systematics reviews, including studies until 2014 and 2016, concluded that there was no increase in the pharynx after rapid maxillary expansion, highlighting that there are no conclusive evidences on this subject because of small number of studies ${ }^{17,18}$. However, some studies published after that systematic review observed increase in total pharyngeal volume after rapid maxillary expansion, both of the nasopharynx and oropharynx ${ }^{19}$, and other studies revealed increase in nasopharynx volume $e^{20,21}$ and reduction of retropalatal area ${ }^{20}$.

Interestingly, Iwasaki et al..$^{22}$ suggested improvement of tongue posture after expansion as a factor increasing the airway. In that study, both individuals with and without nasal obstruction were favored by expansion.

\section{Orthopedic mandibular advancement}

Few studies have compared orthopedic mandibular advancement to improvement of OSA outcomes. A systematic review including only two studies demonstrated that treatment with orthopedic mandibular advancement improved the apnea/ hypopnea index in 5.1 events per hour ${ }^{23}$. No studies in OSA patients have evaluated this treatment using CBCT.

In individuals without OSA, one study observed increase in the total volume of the pharynx, oropharynx and hypopharynx after treatment with Herbst appliance ${ }^{5}$. Study analyzing the Forsus appliance followed by the Crossbow evidenced increase in the oropharynx dimension after treatment ${ }^{24}$, and other study using the Twin block appliance for Class II correction also revealed greater volume of the oropharynx and hypopharynx after treatmen $\mathrm{t}^{25}$. Erbas and Kocadereli $\mathrm{i}^{24}$ reported the increase in oropharynx space to anterior repositioning of the soft palate 
and hyoid bone, and Li et al. ${ }^{25}$ observed a more elliptical shape of the oropharynx after treatment.

\section{Orthopedic maxillary protraction}

This orthopedic procedure aims at anterior traction of the maxilla in cases where it is retroposited. To our knowledge, there are no studies investigating the impact of maxillary protraction treatment of patients with OSA using CBCT imaging.

Two studies performed rapid maxillary expansion associated with maxillary protraction in Class III individuals without OSA revealed an increase in total pharyngeal volume after treat$\mathrm{ment}^{26,27}$. In addition to the total pharyngeal volume, Chen et al. ${ }^{26}$ also observed increased volume of the nasopharynx and retropalatal area.

\section{Orthognathic surgery}

As previously mentioned, orthognathic surgery is considered an alternative treatment for OSA in adults, and the increase in upper airway volume as assessed by СBCT has been thoroughly analyzed.

\section{Maxillomandibular surgery}

A systematic review conducted in 2016 revealed that maxillomandibular surgery is an effective surgical option for OSA. The apnea/hypopnea index was reduced 48 points in AHI, and there was improvement in oxyhemoglobin saturation and sleepiness. Despite the great decrease in AHI, only 38.5\% were cured, because individuals in that sample presented extremely high $\mathrm{AHI}^{28}$. Other systematic review demonstrated that individuals with OSA submitted to maxillomandibular advancement associated with counterclockwise rotation present better outcomes in AHI compared to individuals submitted to maxillomandibular advancement without rotation ${ }^{29}$.

Some systematic reviews were conducted to assess the changes in upper airway volume using CBCT in individual who did or didn't OSA. They evidenced a total airway volume increase of 7.42 and $7.86 \mathrm{~cm}^{3}$ after maxillomandibular surgery $y^{30,31}$.

\section{Mandibular retrusion surgery}

A systematic review analyzing the mandibular retrusion surgery on the incidence or worsening of OSA did not observe incidence of OSA after surgery. It should be highlighted that this review included studies both addressing only mandibular surgeries and mandibular surgeries with maxillary protraction, thus presenting confounding factors. The authors highlighted the need to consider the potential reduction of the airway dimension during treatment planning ${ }^{32}$.

A recent systematic review using CBCT reported that maxillary advancement combined with mandibular retrusion reduced the total airway volume in $1.55 \mathrm{~cm}^{3}$, and isolated mandibular retrusion reduces the total airway volume in $1.89 \mathrm{~cm}^{331}$.

\section{CONCLUSION}

Dentofacial orthopedics and orthognathic surgery have been related to changes in upper airway volume measured by
CBCT. However, the standardized achievement of tomographic images and more controlled and randomized studies are necessary to confirm these findings.

Acknowledgements: The authors thank the Associação Fundo de Apoio à Pesquisa (AFIP), CNPq and CAPES.

Funding: AFIP, CNPq, and CAPES provided material and financial support.

\section{REFERENCES}

1. Masoud AI, Jackson GW, Carley DW. Sleep and airway assessment: A review for dentists. Cranio. 2017;35(4):206-22.

2. Cabral M, de Queiroz Ribeiro LR, Cardeal CM, Bittencourt MA, CrusoéRebello IM, Souza-Machado A. Evaluation of the oropharynx in class I and II skeletal patterns by CBCT. Oral Maxillofac Surg. 2017;21(1):27-31

3. El H, Palomo JM. Airway volume for different dentofacial skeletal patterns. Am J Orthod Dentofacial Orthop. 2011;139(6):e511-21.

4. Oh KM, Hong JS, Kim YJ, Cevidanes LS, Park YH. Three-dimensional analysis of pharyngeal airway form in children with anteroposterior facial patterns. Angle Orthod. 2011;81(6):1075-82.

5. Iwasaki T, Takemoto Y, Inada E, Sato H, Saitoh I, Kakuno E, et al. Threedimensional cone-beam computed tomography analysis of enlargement of the pharyngeal airway by the Herbst appliance. Am J Orthod Dentofacial Orthop. 2014;146(6):776-85.

6. Lenza MG, Lenza MM, Dalstra M, Melsen B, Cattaneo PM. An analysis of different approaches to the assessment of upper airway morphology: a CBCT study. Orthod Craniofac Res. 2010;13(2):96-105.

7. Gurani SF, Di Carlo G, Cattaneo PM, Thorn JJ, Pinholt EM. Effect of Head and Tongue Posture on the Pharyngeal Airway Dimensions and Morphology in Three-Dimensional Imaging: a Systematic Review. J Oral Maxillofac Res. 2016;7(1):e1.

8. Schwab RJ. Upper airway imaging. Clin Chest Med. 1998;19(1):33-54.

9. Katyal V, Pamula Y, Martin AJ, Daynes CN, Kennedy JD, Sampson WJ. Craniofacial and upper airway morphology in pediatric sleep-disordered breathing: Systematic review and meta-analysis. Am J Orthod Dentofacial Orthop. 2013;143(1):20-30.e3.

10. Guijarro-Martínez R, Swennen GR. Cone-beam computerized tomography imaging and analysis of the upper airway: a systematic review of the literature. Int J Oral Maxillofac Surg. 2011;40(11):1227-37.

11. Machado-Júnior AJ, Zancanella E, Crespo AN. Rapid maxillary expansion and obstructive sleep apnea: A review and meta-analysis. Med Oral Patol Oral Cir Bucal. 2016;21(4):e465-9.

12. Fastuca R, Perinetti G, Zecca PA, Nucera R, Caprioglio A. Airway compartments volume and oxygen saturation changes after rapid maxillary expansion: a longitudinal correlation study. Angle Orthod. 2015;85(6):955-61.

13. Caprioglio A, Meneghel M, Fastuca R, Zecca PA, Nucera R, Nosetti L. Rapid maxillary expansion in growing patients: correspondence between 3-dimensional airway changes and polysomnography. Int J Pediatr Otorhinolaryngol. 2014;78(1):23-7.

14. Fastuca R, Meneghel M, Zecca PA, Mangano F, Antonello M, Nucera R, et al. Multimodal airway evaluation in growing patients after rapid maxillary expansion. Eur J Paediatr Dent. 2015;16(2):129-34.

15. Mordente CM, Palomo JM, Horta MC, Souki BQ, Oliveira DD, Andrade I. Upper airway assessment using four different maxillary expanders in cleft patients: A cone-beam computed tomography study. Angle Orthod. 2016;86(4):617-24.

16. Kim SY, Park YC, Lee KJ, Lintermann A, Han SS, Yu HS, et al. Assessment of changes in the nasal airway after nonsurgical miniscrew-assisted rapid maxillary expansion in young adults. Angle Orthod. 2018;88(4):435-41.

17. Ortu E, Giannoni M, Ortu M, Gatto R, Monaco A. Oropharyngeal airway changes after rapid maxillary expansion: the state of the art. Int J Clin Exp Med. 2014;7(7):1632-8.

18. Di Carlo G, Saccucci M, Ierardo G, Luzzi V, Occasi F, Zicari AM, et al. Rapid Maxillary Expansion and Upper Airway Morphology: A Systematic Review on the Role of Cone Beam Computed Tomography. Biomed Res Int. 2017;2017:5460429.

19. Motro M, Schauseil M, Ludwig B, Zorkun B, Mainusch S, Ateş M, et al. Rapid-maxillary-expansion induced rhinological effects: a retrospective multicenter study. Eur Arch Otorhinolaryngol. 2016;273(3):679-87.

20. Almuzian M, Ju X, Almukhtar A, Ayoub A, Al-Muzian L, McDonald JP. Does rapid maxillary expansion affect nasopharyngeal airway? A prospective Cone Beam Computerised Tomography (CBCT) based study. Surgeon. 2018;16(1):1-11. 
21. Izuka EN, Feres MF, Pignatari SS. Immediate impact of rapid maxillary expansion on upper airway dimensions and on the quality of life of mouth breathers. Dental Press J Orthod. 2015;20(3):43-9.

22. Iwasaki T, Saitoh I, Takemoto Y, Inada E, Kakuno E, Kanomi R, et al. Tongue posture improvement and pharyngeal airway enlargement as secondary effects of rapid maxillary expansion: a cone-beam computed tomography study. Am J Orthod Dentofacial Orthop. 2013;143(2):235-45.

23. Huynh NT, Desplats E, Almeida FR. Orthodontics treatments for managing obstructive sleep apnea syndrome in children: A systematic review and meta-analysis. Sleep Med Rev. 2016;25:84-94.

24. Erbas B, Kocadereli I. Upper airway changes after Xbow appliance therapy evaluated with cone beam computed tomography. Angle Orthod. 2014;84(4):693-700

25. Li L, Liu H, Cheng H, Han Y, Wang C, Chen Y, et al. CBCT evaluation of the upper airway morphological changes in growing patients of class II division 1 malocclusion with mandibular retrusion using twin block appliance: a comparative research. PLoS One. 2014;9(4):e94378.

26. Chen X, Liu D, Liu J, Wu Z, Xie Y, Li L, et al. Three-Dimensional Evaluation of the Upper Airway Morphological Changes in Growing Patients with Skeletal Class III Malocclusion Treated by Protraction Headgear and Rapid Palatal Expansion: A Comparative Research. PLoS One. 2015;10(8):e0135273.
27. Pamporakis P, Nevzatoğlu S, Küçükkeles N. Three-dimensional alterations in pharyngeal airway and maxillary sinus volumes in Class III maxillary deficiency subjects undergoing orthopedic facemask treatment Angle Orthod. 2014;84(4):701-7.

28. Zaghi S, Holty JE, Certal V, Abdullatif J, Guilleminault C, Powell NB, et al. Maxillomandibular Advancement for Treatment of Obstructive Sleep Apnea: A Meta-analysis. JAMA Otolaryngol Head Neck Surg. 2016;142(1):58-66

29. Knudsen TB, Laulund AS, Ingerslev J, Homøe P, Pinholt EM. Improved apnea-hypopnea index and lowest oxygen saturation after maxillomandibular advancement with or without counterclockwise rotation in patients with obstructive sleep apnea: a meta-analysis. J Oral Maxillofac Surg. 2015;73(4):719-26.

30. Rosário HD, Oliveira GM, Freires IA, de Souza Matos F, Paranhos LR Efficiency of bimaxillary advancement surgery in increasing the volume of the upper airways: a systematic review of observational studies and meta-analysis. Eur Arch Otorhinolaryngol. 2017;274(1):35-44.

31. Christovam IO, Lisboa CO, Ferreira DM, Cury-Saramago AA, Mattos CT. Upper airway dimensions in patients undergoing orthognathic surgery: a systematic review and meta-analysis. Int J Oral Maxillofac Surg. 2016;45(4):460-71.

32. Canellas JV, Barros HL, Medeiros PJ, Ritto FG. Sleep-disordered breathing following mandibular setback: a systematic review of the literature Sleep Breath. 2016;20(1):387-94. 